\title{
Synthesis of zeolites from coal fly ash using mine waters
}

\author{
Nicholas M. Musyoka, Leslie F. Petrik, Ojo O. Fatoba and Eric Hums
}

\begin{abstract}
:
In this study mine waters obtained from coal mining operations in South Africa were used as a substitute for pure water during the synthesis of zeolites from South African coal fly ash. Procedures that had been optimized to produce single phase zeolite Na-P1 and $\mathrm{X}$ using pure water were employed independently. The use of circumneutral mine water resulted in similar quality zeolite $\mathrm{Na}-\mathrm{P} 1$ and $\mathrm{X}$ whereas the use of acidic mine drainage led to the formation of a single phase hydroxysodalite zeolite. Since these two wastes (fly ash and mine waters) are found in close proximity to each other, this study demonstrates that they can be used to ameliorate each other and at the same time produce saleable zeolitic products that can be used to offset their costs of disposal and treatment.
\end{abstract}

\section{Introduction}

Coal combustion is heavily relied upon during the production of electricity in many countries worldwide. In South Africa, almost 90\% of electricity is derived from coal combustion (Eskom, 2011). According to the World coal association, the abundance of coal re-serves and the guaranteed supply is expected to sustain the existing coal power stations for many years to come as well as prompt construction of new power stations especially in developing countries (World Coal association publication, 2005). During the coal mining and coal combustion operations, many un-avoidable by-products are produced which persistently present on-going environmental problems. Some of these wastes include; mine waters, produced during the coal mining operation and fly ash, generated during the coal combustion process. Both of these wastes are considered an environmental liability and require expensive technologies to treat and dispose. Of the total fly ash produced in South Africa, with the annual estimate of about 36.2 million tonnes, only about $5 \%$ is recycled while the rest is disposed of in ash dumps (Eskom, 2011).

During the coal mining operation, the type of mine water generated, either acidic or circumneutral, is dependent on the geology of the bedrock in the coal mine (Madzivire et al., 2010). The acidic waters which are referred to as acid mine drainage (AMD) result when coal seams and other pyrite containing rocks are exposed to air and water causing production of sulfuric acid $\left(\mathrm{H}_{2} \mathrm{SO}_{4}\right)$. The rate of formation of AMD is accelerated by the presence of acidophilic bacteria (Prasad and Mortimer, 2011). The sulfuric acid 
dissolves and mobilizes elements such as $\mathrm{Fe}, \mathrm{Al}, \mathrm{Mn}$ among others as it flows through rocks and is characterized by a $\mathrm{pH}$ as low as about 2 (Feng et al., 2000). When this acidic water is left untreated and let to discharge in streams and other surface drainage, it can lead to the disappearance of aquatic life and also lower the quality of the water rendering it unusable because of the low $\mathrm{pH}$ and high toxic metal concentration. As the water flows from the mining source, it continues to expose new pyrite surfaces which enable other additional reaction to take place between sulfuric acid and host rock minerals (Prasad and Mortimer, 2011). In the case where the AMD flows past dolomite rich minerals, the AMD undergoes partial neutralization to form circumneutral mine waters (CMW) which is often classified to as either $\mathrm{Ca}-\mathrm{Mg}$ or Na-rich (Madzivire et al., 2010). Circumneutral mine waters lack the usual orange-yellow color of the AMD because most of the iron is precipitated out. Since the coal mines and coal combustion power plants are mostly found in close proximity to each other, it would be of interest to develop a holistic strategy to ameliorate their byproducts by taking advantage of the economies of scale.

Many researchers have investigated different ways of recycling fly ash and an excellent review was presented by Ahmaruzzaman (2010). On the other hand, several techniques have been developed and tested for treating mine waters and are mainly classified as either active and passive systems (Prasad and Mortimer, 2011). Most of these technologies are expensive and unsustainable. Of the many applications of fly ash, zeolite synthesis has been reported to be of great interest due to the fact that zeolites have wide industrial application and their sale can offset disposal cost as well as eradicate the environmental liability. Since the initial studies that were reported by Holler and Wirsching, 1985, many different types of zeolites have been synthesized from fly ash by varying the synthesis conditions (Querol et al., 2002). Most of these studies utilized pure water during the synthesis process apart from a few studies that have concentrated on the use of seawater (Lee et al., 2001; Belviso et al., 2010). In our previous study (Musyoka et al., 2011), we showed that waste industrial brine could be used during the zeolitization process and a single phase hydroxysodalite zeolite was obtained from South African coal fly ash. Another study conducted by Vadapalli et al., 2010 showed that co-disposal solids, generated from the active treatment of acid mine drainage with coal fly ash, could be used as a feedstock for zeolite synthesis even though pure water was used during the synthesis procedure. The current study seeks to investigate the direct use of different types of mine waters to synthesize different types of zeolites.

The motivation for this work was inspired by the need for complete industrial waste reuse. Having no doubt that the reliance on coal for energy production will continue with further prospects of increase in future due to the increasing demand for industrial and domestic energy, the volume of generated waste will continues to grow in direct proportion to the increased consumption. It should be recognized that creative and innovative ways are required to deals with the ever increasing quantities of wastes to reduce their environmental burden associated with disposal and also cut down the high cost of treatment. More importantly, research that treats these wastes as valuable 
resources should be encouraged. In this regard, the use of these two wastes in zeolite synthesis will not only offer a potentially capital savings option for disposal of these wastes but will also be advantageous to the coal mines and power stations since it will enable constructive use of the large volumes of waste that they generate. The generated zeolitic products can be sold because zeolites are industrially important materials since they have a wide range of applications such as in catalysis (Hui and Chao, 2008), water treatment (Moreno et al., 2001), $\mathrm{CO}_{2}$ capture (Lee and Jo, 2010) among others.

\section{Experimental}

\subsection{Materials and characterizations}

Coal fly ash was obtained from a power plant located in the Mpumalanga province of South Africa and was stored in sealed containers before use to preserve its compositional integrity. The two types of mine waters (acid and circumneutral) were collected from coal mines located in Mpumalanga province in South Africa. Their pH was measured using a HANNA HI 991301 portable pH/ EC/TDS/temperature meter. X-ray diffraction (XRD) analysis of the feedstock (fly ash) and zeolitic products was performed using a Philips X-ray diffractometer. The phase identification was conducted by searching and matching the obtained spectra with the powder diffraction file data base with the help of JCPDS (Joint committee of powder diffraction standards) files for inorganic compounds. Multielement analysis was conducted using Philips PW 1480 X-ray spectrometer. Hitachi X-650 scanning electron micro-analyser was used for morphological analysis and the samples were mounted on aluminum pegs and coated with a thin film of gold to make them conductive. The concentrations of ionic species in the mine water were measured by the use of a Varian Radial inductively coupled plasma atomic emission (ICP-AES).

\subsection{Zeolite synthesis}

The synthesis conditions for producing zeolite Na-P1 and X were initially identified and optimized using pure water before substitution of mine water was carried out. The procedure applied for each zeolite type is as follows;

\subsubsection{Zeolite Na-P1}

The optimization experiments for a two-step synthesis procedure for zeolite Na-P1 using pure water were conducted and reported earlier (Musyoka et al., 2011). The synthesis conditions applied using the mine waters as the solvent were; the ageing temperature and time were kept constant at $47^{\circ} \mathrm{C}$, and $48 \mathrm{~h}$ respectively. After ageing, the resulting solution was transferred in aliquots of $10 \mathrm{ml}$ into a $23 \mathrm{ml}$ Parr bomb and crystallized at 140

\subsubsection{Zeolite $X$}

The as-received fly ash was fused with sodium hydroxide in the ratio of $1: 1.2$ at $550{ }^{\circ} \mathrm{C}$ for $1.5 \mathrm{~h}$ to convert the insoluble fly ash mineral phase to soluble sodium 
aluminosilicate phase. The resulting solid material was cooled down and dissolved in the mine water in a ratio of 1:5 which was followed by stirring for $2 \mathrm{~h}$. The resulting mixture was poured into the Teflon cups of Parr bombs and put into a Memmert hot air oven for hydrothermal crystallization at $80^{\circ} \mathrm{C}$ for $9 \mathrm{~h}$.

In both cases, after hydrothermal treatment, the liquid phase was separated from the synthesis product and thoroughly washed using ultra-pure water by filtration until a filtrate $\mathrm{pH}$ of $9-10$ was obtained and dried overnight at $90{ }^{\circ} \mathrm{C}$ prior to characterization.

Table 1

XRF chemical analysis of the as-received fly ash: Major and minor elements.

\begin{tabular}{lcllrr}
\hline $\begin{array}{l}\text { Major element } \\
\text { (oxide) }\end{array}$ & $\begin{array}{l}\text { Average } \\
\text { (mass \%) }\end{array}$ & $\begin{array}{l}\text { Std. } \\
\text { dev. }\end{array}$ & $\begin{array}{l}\text { Minor } \\
\text { elements }\end{array}$ & $\begin{array}{l}\text { Average } \\
\text { (ppm) }\end{array}$ & \multicolumn{1}{c}{$\begin{array}{c}\text { Std. } \\
\text { dev. }\end{array}$} \\
\hline $\mathrm{SiO}_{2}$ & 51.52 & 0.06 & $\mathrm{Sr}$ & 1369.17 & 8.68 \\
$\mathrm{Al}_{2} \mathrm{O}_{3}$ & 27.52 & 0.10 & $\mathrm{Zr}$ & 639.45 & 2.41 \\
$\mathrm{CaO}$ & 6.62 & 0.05 & $\mathrm{Ba}$ & 399.78 & 16.01 \\
$\mathrm{Fe}_{2} \mathrm{O}_{3}$ & 4.96 & 0.05 & $\mathrm{Cr}$ & 233.29 & 2.47 \\
$\mathrm{MgO}_{\mathrm{TiO}}$ & 1.96 & 0.01 & $\mathrm{Ce}$ & 219.12 & 8.13 \\
$\mathrm{~K}_{2} \mathrm{O}$ & 1.06 & 0.00 & $\mathrm{Ni}$ & 106.06 & 6.82 \\
$\mathrm{P}_{2} \mathrm{O}_{5}$ & 0.57 & 0.01 & $\mathrm{Cu}$ & 114.42 & 19.82 \\
$\mathrm{Na}_{2} \mathrm{O}$ & 0.27 & 0.00 & $\mathrm{Y}$ & 93.78 & 1.58 \\
$\mathrm{MnO}$ & 0.09 & 0.00 & $\mathrm{Zn}$ & 94.88 & 15.64 \\
$\mathrm{SO}_{3}$ & 0.05 & 0.00 & $\mathrm{~Pb}$ & 88.23 & 7.19 \\
$\mathrm{LI}^{\mathrm{O}}$ & 0.06 & 0.00 & $\mathrm{~V}$ & 81.94 & 4.65 \\
$\mathrm{Sum}$ & 5.70 & 0.00 & $\mathrm{Rb}$ & 60.13 & 0.68 \\
$\mathrm{SiO}_{2} / \mathrm{Al}_{2} \mathrm{O}_{3}$ & 100.39 & 0.04 & $\mathrm{Th}$ & 42.89 & 0.43 \\
& 1.87 & & $\mathrm{Nb}$ & 39.59 & 1.13 \\
& & & $\mathrm{U}$ & 30.04 & 10.62 \\
& & & $\mathrm{Co}$ & 25.45 & 3.02 \\
& & & $\mathrm{Mo}$ & 2.23 & 0.01 \\
\hline
\end{tabular}

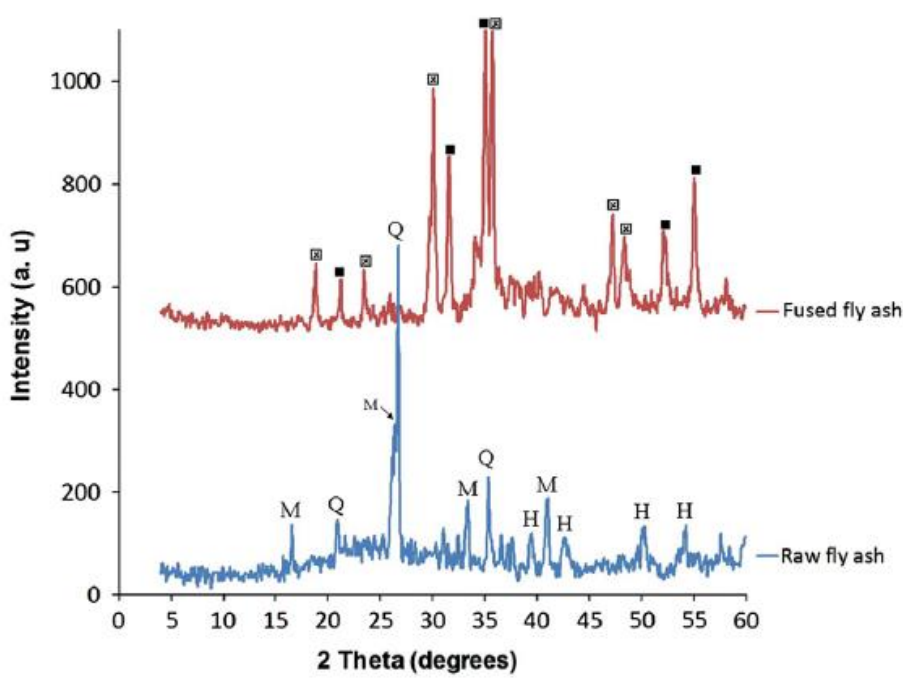

Fig. 1. XRD patterns of the as-received (raw) and alkali fused fly ash $(Q=Q u a r t z$, $\mathrm{M}=$ Mullite, $\mathrm{H}=$ Hematite, $\boldsymbol{X}=\mathrm{Na}_{2} \mathrm{SiO}_{3}, \mathbf{\square}=\mathrm{Na}_{2} \mathrm{AlO}_{2}$ ). 


\section{Results and discussion}

The elemental composition (major and trace elements) of the as-received fly ash is presented in Table 1. According to the specification of ASTM C618-84, this fly ash can be classified as class $\mathrm{F}$ type because the total weight percent of silicon oxide, alumina, and iron oxide is larger than $70 \mathrm{wt} \%$. The $\mathrm{SiO}_{2} / \mathrm{Al}_{2} \mathrm{O}_{3}$ ratio was found to be 1.87 and was a good predictor of the potential to synthesize most low silica zeolites. The low Ca content in the as-received fly ash also meant that this fly ash could be a good starting material for zeolite synthesis because higher amounts of $\mathrm{Ca}$ are associated with suppression of zeolite crystallization process (Catalfamo et al., 1997). The fly ash was also noted to have relatively higher levels of $\mathrm{Sr}, \mathrm{Zr}, \mathrm{Ba}, \mathrm{Cr}$, and Ce which ranged between 219 and $1369 \mathrm{ppm}$. The concentration of the other trace elements was found to be less than 200 ppm. The distribution of trace elements in fly ash, just like the major elements, can be related to the coal sources and also on the coal combustion technology used.

Fig. 1 compared the mineralogy of the as-received and alkali fused fly ash as determined by the XRD technique. As noted from the X-ray diffraction patterns, the major crystalline phases in the as-received fly ash were found to be Quartz $\left(\mathrm{SiO}_{2}\right)$, Mullite $\left(3 \mathrm{Al}_{2} \mathrm{O}_{3} \cdot \cdot \mathrm{SiO}_{2}\right)$, and Hematite $\left(\mathrm{Fe}_{2} \mathrm{O}_{3}\right)$. The glassy amorphous material was identified as the broad hump in the XRD spectra which was observed to occur between $20^{\circ}$ and $40^{\circ} 2 \mathrm{~h}$. This hump was also identified by other researchers (Inada et al., 2005; Ríos and Williams, 2008). The main mineral phases in the fused fly ash were Na-aluminate $\left(\mathrm{Na}_{2} \mathrm{AlO}_{3}\right)$ and Na-silicate $\left(\mathrm{Na}_{2} \mathrm{SiO}_{3}\right)$ and no presence of Quartz, Hematite and Mullite remained. These new mineral phases were formed from transformation that occurred during the solid-state reactions of the as-received fly ash with the $\mathrm{NaOH}$ in the presence of heat. The respective SEM micrographs that were obtained for the as-received Arnot fly ash and fused fly ash are shown in Fig. 2. Majority of the as-received fly ash particles shown in Fig. 2a were observed to be generally spherical in shape. The spherical shaped particles are mostly related to the cooling effect since fly ash particles solidify while suspended in the flue gases (Kutchko and Kim, 2006). Their smooth surface is attributed to the fact that these particles are covered with an amorphous glass phase (Inada et al., 2005). From the morphological analysis of fused fly ash, presented in Fig. 2b, the predominant spherical particles that had been observed in the SEM micrograph of the as-received fly ash had been transformed into an agglomerated porous mass that was laurel-green in color and was easy to grind.

The average elemental composition of the mine waters used in this study is reported in Table 2. Although the generic term 'acid rock drainage' is often used to describe mine water discharges, the $\mathrm{pH}$ for the circumneutral water and acid mine drainage water was found to be 6.5 and 2.5 respectively. The low $\mathrm{pH}$ of the acidic mine waters is a known characteristic of these waters (Feng et al., 2000). The almost neutral characteristic of the circumneutral water arises due to the partial neutralization of the acidic mine waters as it flows past dolomite rich minerals (Madzivire et al., 2010). From the results presented in Table 2, it is evident that the acidic mine water (AMD) had a high concentration of Fe (4694 mg/L), Ca (458.40 mg/L), Mg (385.50 mg/L), Al (612.60 mg/L) and $\mathrm{Mn}(87.75$ 
$\mathrm{mg} / \mathrm{L})$ as well as high concentration of $\mathrm{SO}^{2-}(42862 \mathrm{mg} / \mathrm{L})$ and $\mathrm{Cl}^{-}(9.8 \mathrm{mg} / \mathrm{L})$. The presence of these elements in the acidic mine water is due to the effect of sulfuric acid which dissolves and mobilizes the elements from the surrounding rocks as it flows around or beyond the mining area. The chemical composition of the generated acidic mine water has been reported to be mainly influenced by the geology of the bedrock in the coal mine (Madzivire et al., 2010). Comparing the chemical compositions of the acidic mine water with that of the circumneutral mine water (CNW), it can be noted that the CNW water had a high concentration of $\mathrm{Na}(952 \mathrm{mg} / \mathrm{L})$ as well as a comparatively lower amounts of $\mathrm{Mg}(37.75 \mathrm{mg} / \mathrm{L}), \mathrm{Ca}(18.81 \mathrm{mg} / \mathrm{L}), \mathrm{K}(7.60 \mathrm{mg} / \mathrm{L})$ as well as $\mathrm{SO}_{4}^{2-}(1475.25 \mathrm{mg} / \mathrm{L})$ and $\mathrm{Cl}^{-}(24 \mathrm{mg} / \mathrm{L})$.

Table 2

Chemical analysis of circumneutral (CNW) and acid drainage (AMD) mine waters.

\begin{tabular}{lll}
\hline & $\mathrm{CNW}(\mathrm{mg} / \mathrm{l})$ & $\mathrm{AMD}(\mathrm{mg} / \mathrm{l})$ \\
\hline Cationic species & & \\
$\mathrm{Fe}$ & 0.06 & 4694.00 \\
$\mathrm{Na}$ & 952.00 & 67.74 \\
$\mathrm{Ca}$ & 18.81 & 458.40 \\
$\mathrm{Mg}$ & 37.75 & 385.50 \\
$\mathrm{~K}$ & 7.60 & $\mathrm{nd}$ \\
$\mathrm{Mn}$ & 0.01 & 87.75 \\
$\mathrm{Si}$ & 1.24 & 31.17 \\
$\mathrm{Al}$ & $\mathrm{nd}$ & 612.60 \\
$\mathrm{P}$ & $\mathrm{nd}$ & 0.54 \\
$\mathrm{~B}$ & 1.02 & $\mathrm{nd}$ \\
$\mathrm{Ni}$ & $\mathrm{nd}$ & 2.95 \\
$\mathrm{Ba}$ & 0.02 & $\mathrm{nd}$ \\
$\mathrm{Co}$ & $\mathrm{nd}$ & 1.03 \\
$\mathrm{Cu}$ & 0.02 & 2.51 \\
$\mathrm{Li}$ & $\mathrm{nd}$ & 0.36 \\
$\mathrm{~Pb}$ & 0.11 & $\mathrm{nd}$ \\
$\mathrm{Sr}$ & 1.02 & 1.09 \\
$\mathrm{Zn}$ & $\mathrm{nd}$ & 18.98 \\
$\mathrm{Anionic}^{2-}$ species & & \\
$\mathrm{SO}_{4}^{2-}$ & 1475.25 & 42,862 \\
$\mathrm{Cl}$ & 24 & 9.8 \\
\hline
\end{tabular}

nd $=$ Not detected. 

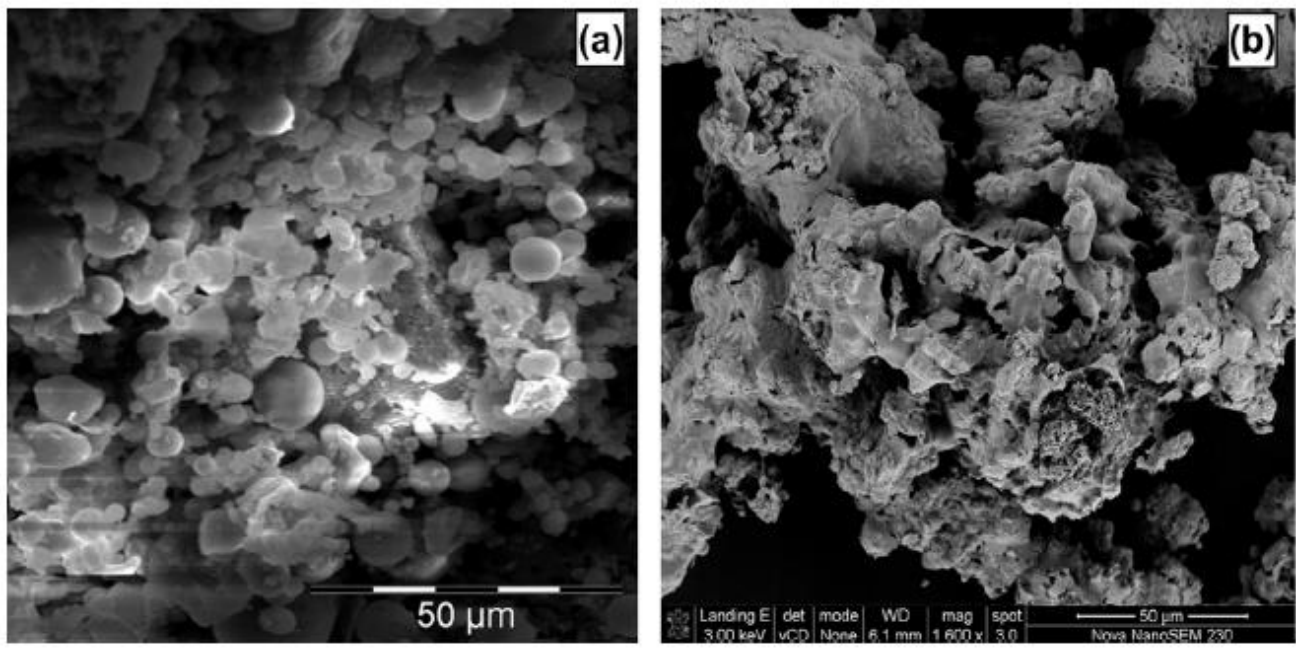

Fig. 2. SEM micrographs of (a) as-received Arnot fly ash (b) fused fly ash.
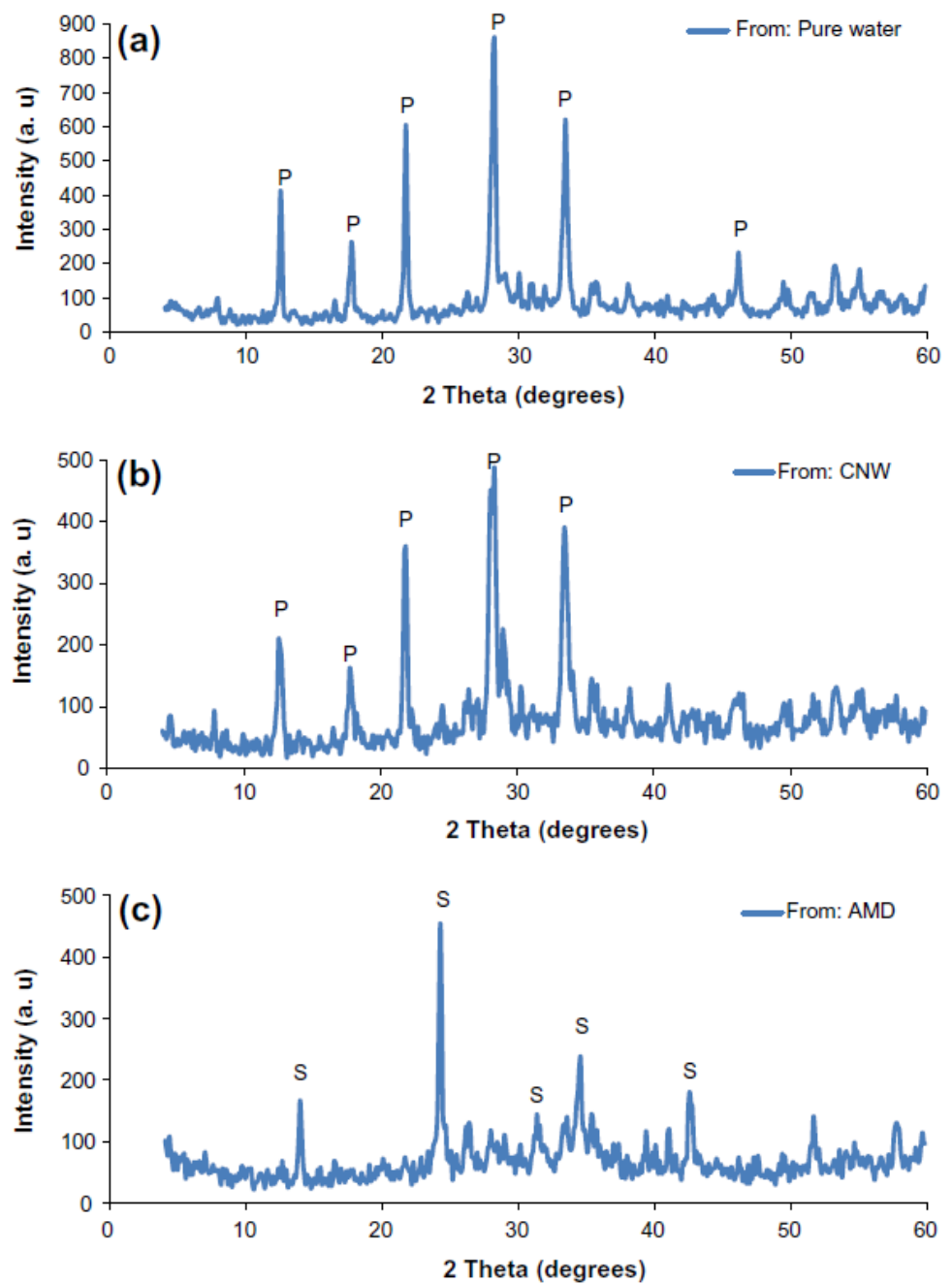

Fig. 3. XRD patterns of zeolite Na-P1 (P) and hydroxysodalite (S) synthesized from the asreceived fly ash using (a) pure water (b) circumneutral mine water and (c) acid mine drainage water. 

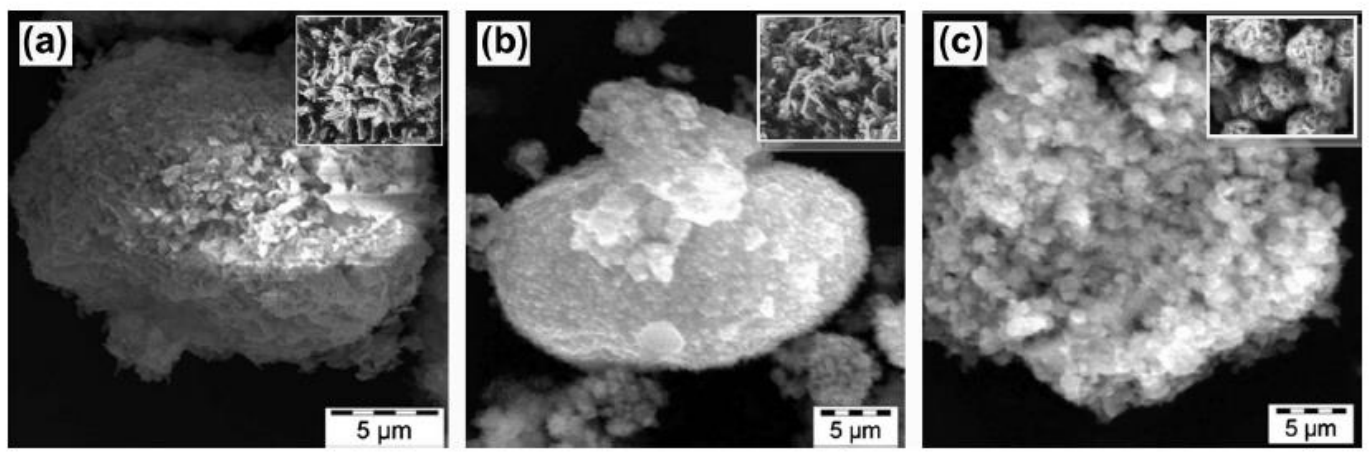

Fig. 4. SEM micrographs of zeolite Na-P1 and hydroxysodalite synthesized from the asreceived fly ash using (a) pure water (b) circumneutral mine water and (c) acid mine drainage water.
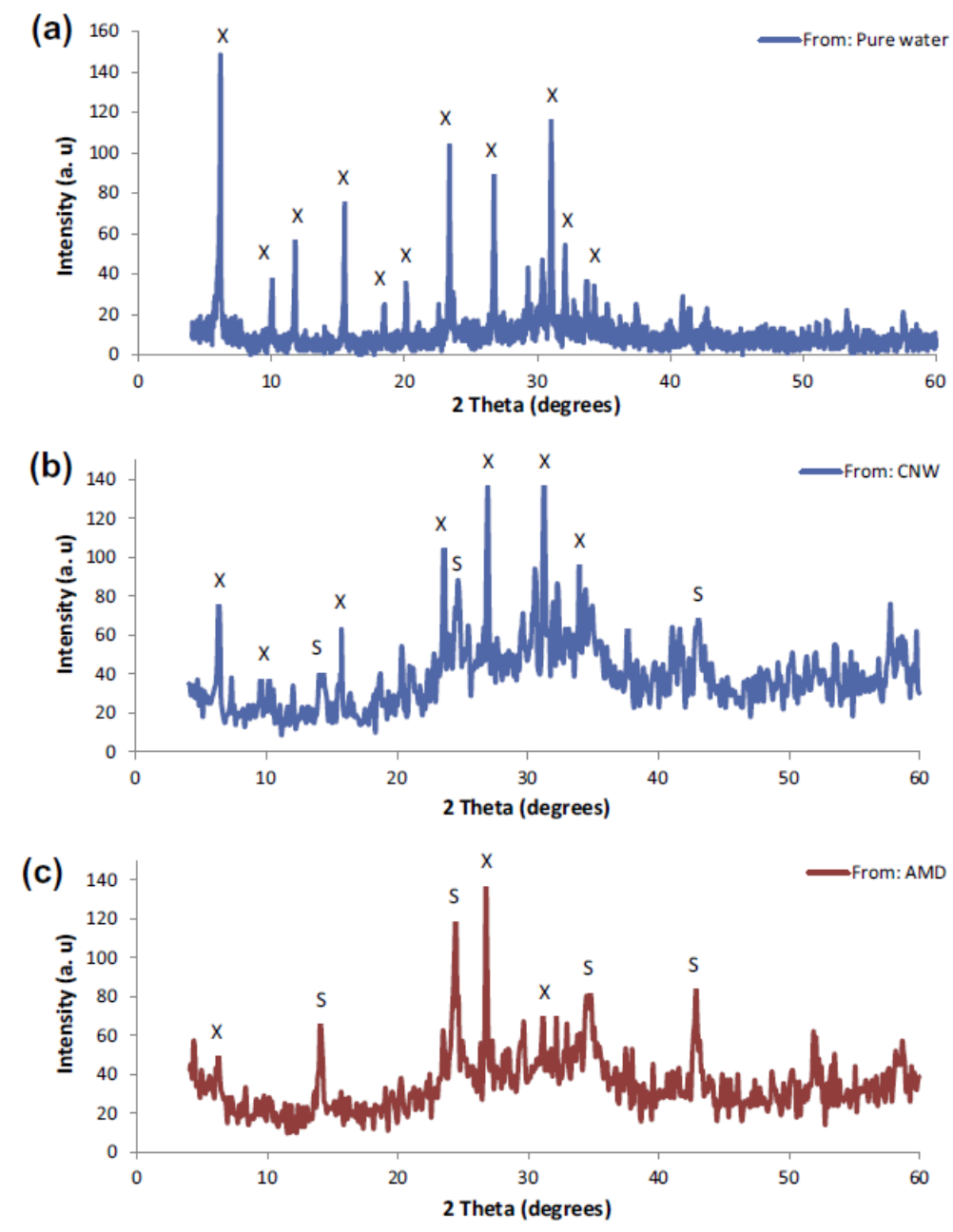

Fig. 5. XRD patterns of zeolite $X(X)$ and hydroxysodalite $(\mathrm{S})$ synthesized from fused fly ash using (a) pure water (b) circumneutral mine water and (c) acid mine drainage water. 

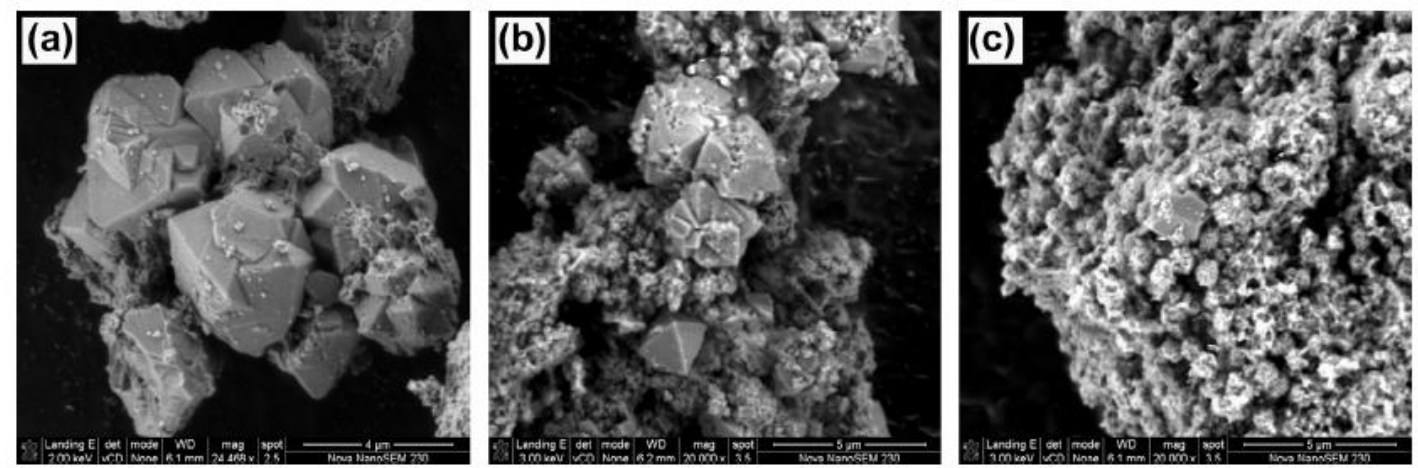

Fig. 6. SEM micrographs of zeolite $\mathrm{X}$ and hydroxysodalite synthesized from the fused fly ash using (a) pure water (b) circumneutral mine water and (c) acid mine drainage water.

The high concentration of $\mathrm{Na}$ in the circumneutral mine water makes the CNW to be classified as Na-rich mine water. It was also noticeable that the acidic mine water had an orange-yellow color because of the high concentration of Fe.

Fig. 3 presents the XRD patterns for the synthesis products obtained when zeolite NaP1 was targeted from the as-received fly ash using pure water, circumneutral mine water and acid mine drainage water as the synthesis solvent. When pure water and circumneutral waters were used during the synthesis process a single phase zeolite Na-P1 was noted to crystallize. The diffractograms also showed that the crystalline phases originally in the fly ash were mostly absent in the resulting zeolitic material since during the zeolite formation process both the amorphous and crystalline phases were dissolved to form the zeolite nuclei which are known to grow to form the visible zeolite crystals.

Table 3

Comparative chemical analyses (major and minor elements) of synthesis products obtained when the different solvents (pure water, circumneutral (CNW) and acid mine water $(\mathrm{AMD})$ ) were used when zeolite Na-P1 was targeted starting from as-received fly ash slurry.

\begin{tabular}{|c|c|c|c|c|c|c|c|}
\hline \multicolumn{4}{|c|}{ Major elements (average mass\%) } & \multicolumn{4}{|c|}{ Minor elements (average ppm) } \\
\hline $\begin{array}{l}\text { Elements } \\
\text { (oxide) }\end{array}$ & Pure water & CNW water & AMD water & Elements & Pure water & CNW water & AMD water \\
\hline $\mathrm{SiO}_{2}$ & 36.69 & 36.44 & 34.7 & $\mathrm{~V}$ & 90 & 173 & 175 \\
\hline $\mathrm{Al}_{2} \mathrm{O}_{3}$ & 25.17 & 23 & 22.82 & $\mathrm{Cr}$ & 84 & 157 & 156 \\
\hline $\mathrm{Na}_{2} \mathrm{O}$ & 6.53 & 12.03 & 13.57 & Co & 20 & 361 & 58 \\
\hline $\mathrm{CaO}$ & 6.07 & 5.83 & 5.9 & $\mathrm{Ni}$ & 36 & 426 & 79 \\
\hline $\mathrm{Fe}_{2} \mathrm{O}_{3}$ & 2.28 & 4.4 & 6.4 & $\mathrm{Cu}$ & 216 & 299 & 32 \\
\hline MgO & 2.21 & 1.62 & 1.8 & $\mathrm{Zn}$ & 35 & 86 & 104 \\
\hline $\mathrm{TiO}_{2}$ & 1.58 & 1.42 & 1.37 & $\mathrm{Ga}$ & 19 & 19 & 22 \\
\hline $\mathrm{K}_{2} \mathrm{O}$ & 0.13 & 0.12 & 0.14 & $\mathrm{Rb}$ & 17 & 14 & 11 \\
\hline $\mathrm{P}_{2} \mathrm{O}_{5}$ & 0.04 & 0.19 & 0.09 & $\mathrm{Sr}$ & 525 & 902 & 851 \\
\hline $\mathrm{MnO}$ & 0.06 & 0.06 & 0.1 & $\mathrm{Y}$ & 39 & 66 & 74 \\
\hline $\mathrm{Cr}_{2} \mathrm{O}_{3}$ & 0.04 & 0.02 & 0.02 & $\mathrm{Zr}$ & 260 & 390 & 368 \\
\hline LOI & 11.92 & 14.18 & 12.99 & $\mathrm{Nb}$ & 18 & 33 & 27 \\
\hline $\mathrm{H}_{2} \mathrm{O}$ & 7.04 & 0.68 & 0.11 & $\mathrm{Ba}$ & 341 & 704 & 711 \\
\hline Sum & 99.76 & 100 & 100 & $\mathrm{Ce}$ & 73 & 164 & 196 \\
\hline \multirow[t]{4}{*}{$\mathrm{SiO}_{2} / \mathrm{Al}_{2} \mathrm{O}_{3}$ ratio } & 1.46 & 1.58 & 1.52 & $\mathrm{Nd}$ & 30.62 & 65.69 & 77.86 \\
\hline & & & & $\mathrm{Pb}$ & 39.49 & 51.83 & 46.48 \\
\hline & & & & Th & 25.36 & 40.2 & 38.69 \\
\hline & & & & $\mathrm{U}$ & 5.34 & 8.25 & 4.59 \\
\hline
\end{tabular}


Comparative chemical analyses (major and minor elements) of synthesis products obtained when the different solvents (pure water, circumneutral (CNW) and acid mine water (AMD)) were used when zeolite $\mathrm{X}$ was targeted starting from fused fly ash slurry.

\begin{tabular}{|c|c|c|c|c|c|c|c|}
\hline \multicolumn{4}{|c|}{ Major elements (average mass \%) } & \multicolumn{4}{|c|}{ Minor elements (average ppm) } \\
\hline $\begin{array}{l}\text { Elements } \\
\text { (oxide) }\end{array}$ & Pure water & CNW water & AMD water & Elements & Pure water & CNW water & AMD water \\
\hline $\mathrm{SiO}_{2}$ & 34.86 & 38.39 & 36.37 & $\mathrm{Sr}$ & 779 & 879 & 741 \\
\hline $\mathrm{Al}_{2} \mathrm{O}_{3}$ & 19.43 & 22.22 & 19.52 & $\mathrm{~V}$ & 141 & 158 & 168 \\
\hline $\mathrm{Na}_{2} \mathrm{O}$ & 15.56 & 10.21 & 11.43 & $\mathrm{Ce}$ & 140 & 154 & 200 \\
\hline $\mathrm{CaO}$ & 4.96 & 5.30 & 5.35 & $\mathrm{Zr}$ & 341 & 361 & 312 \\
\hline $\mathrm{Fe}_{2} \mathrm{O}_{3}$ & 3.28 & 3.22 & 9.50 & $\mathrm{Y}$ & 57 & 63 & 77 \\
\hline $\mathrm{MgO}$ & 1.38 & 1.53 & 1.84 & Nd & 56 & 62 & 79 \\
\hline $\mathrm{K}_{2} \mathrm{O}$ & 0.17 & 0.12 & 0.10 & Co & 39 & 58 & 77 \\
\hline $\mathrm{P}_{2} \mathrm{O}_{5}$ & 0.07 & 0.03 & 0.03 & Th & 35 & 38 & 33 \\
\hline $\mathrm{MnO}$ & 0.04 & 0.06 & 0.13 & $\mathrm{Zn}$ & 44 & 55 & 160 \\
\hline $\mathrm{Cr}_{2} \mathrm{O}_{3}$ & 0.01 & 0.01 & 0.01 & $\mathrm{~Pb}$ & 41 & 47 & 41 \\
\hline LOI & 17.06 & 16.12 & 13.81 & $\mathrm{Nb}$ & 29 & 29 & 24 \\
\hline $\mathrm{H}_{2} \mathrm{O}$ & 1.94 & 1.40 & 0.74 & $\mathrm{U}$ & 6 & 6 & 5 \\
\hline Sum & 100.00 & 100.00 & 100.00 & $\mathrm{Cu}$ & nd & 105 & nd \\
\hline \multirow{2}{*}{$\mathrm{SiO}_{2} / \mathrm{Al}_{2} \mathrm{O}_{3}$ ratio } & 1.79 & 1.73 & 1.86 & $\mathrm{Ga}$ & 15 & 14 & 12 \\
\hline & & & & $\mathrm{Rb}$ & 14 & 12 & 9 \\
\hline
\end{tabular}

nd $=$ Not detected.

Zeolite Na-P1, which is a member of gismondine group, has its structural framework built of 4- and 8-membered rings and has applications in water treatment (Moreno et al., 2001). The formation of single phase zeolite Na-P1 using circumneutral mine water, just like when pure water was used, shows that the extra cations in the circumneutral mine water did not have any profound effect in the crystallization of this specific zeolite. The obtained yield was almost the same when the two types of synthesis solvents were used. Upon using acid mine water as the synthesis solvent, it was interesting to note that only a single phase hydroxysodalite zeolite could be obtained as shown in Fig. 4c. Hydroxysodalite belongs to the sodalite group of zeolites and its structure comprises of frameworks of 4- and 6membered rings of $\mathrm{SiO}_{4}$ and $\mathrm{AlO}_{4}$ tetrahedra. The failure to obtain a single phase zeolite $\mathrm{Na}-\mathrm{P} 1$ could be attributed to the presence of higher concentrations of $\mathrm{Fe}$ and $\mathrm{Ca}$ in the acid mine drainage water.

Morphological analysis of the synthesized product (Fig. 4) served to complement the respective XRD analysis. In the case where ultra-pure and circumneutral mine waters were used during the procedure for synthesis of zeolite $\mathrm{Na}-\mathrm{P} 1$, agglomerates of cotton-like morphology was observed as seen in Fig. 4a and b. For studies that have resulted in incomplete transformation of fly ash to zeolites, Murayama et al. (2002) suggested that zeolite crystallization takes place at the interface between the undissolved fly particle and the alkali solution leading to deposition of zeolite crystals which cut the supply of aluminate and silicate ions that are required for further zeolitization. Where acid mine drainage water was used, crystals that had 'ball-of-yarn-like' morphology which are typical for hydroxysodalite could be observed as shown in Fig. 4c. The formation of both single phases of zeolite NaP1 and hydroxysodalite was advantageous since the presence of non-zeolitic phases in the converted products is known to limit and hinder applications of these zeolites especially in applications as ion-exchangers and/or in catalysis. 
The comparative XRD analysis of the synthesis products obtained when zeolite X was targeted using pure water, circumneutral mine water or acid mine drainage mine water, is presented in Fig. 5. When the optimized hydrothermal synthesis conditions for producing zeolite $\mathrm{X}$ were applied using circumneutral mine water, a mixture of hydroxysodalite and zeolite $\mathrm{X}$ was obtained, which was unlike the single phase zeolite $\mathrm{X}$ obtained when pure water was used (Fig. 5a). Use of the acid mine water led to the formation of hydroxysodalite zeolite with trace amounts of zeolite $\mathrm{X}$. The background hump appearing between $20^{\circ}$ and $40^{\circ} 2 \mathrm{~h}$ in the XRD spectra obtained from use of the two mine waters provides evidence for the presence of an amorphous glassy phase meaning that the fused precursor species had not been fully transformed into zeolitic material. This observation could mean that the hydrothermal synthesis conditions of 80 ${ }^{\circ} \mathrm{C}$ for $9 \mathrm{~h}$ could still need further optimization. In the corresponding morphological analysis, the single phase zeolite $\mathrm{X}$ obtained using pure water had the typical pyramidal octahedral shaped crystal morphology (Fig. 6a) whereas a mixture of small globular-shaped aggregates of hydroxy-sodalite crystals and the pyramidal octahedralshaped crystals of zeolite X could be observed when the circumneutral mine waters were used (Fig. 6b). Fig. 6c confirms that the obtained zeolitic product when acid mine water was mainly sodalite. The failure to obtain single phase zeolite $\mathrm{X}$, unlike in the case when zeolite Na-P1 was targeted using mine waters, could be attributed to their structural differences which is also thought to be a contributing factor that influences their formation mechanisms. It could also be due to the changes in the molar regimes brought by the extra $\mathrm{Al}$ and $\mathrm{Na}$ in the acid mine water.

The comparative chemical analyses of the synthesis products obtained when the different solvents (pure water, circumneutral and acid mine water) were used when zeolite Na-P1 and X were targeted are presented in Tables 3 and 4 respectively. It can be noted that the content of $\mathrm{Na}_{2} \mathrm{O}$ in the zeolitic samples was relatively higher than it was originally in the fly ash (Table 1). This difference is attributed to the additional $\mathrm{NaOH}$ that had been used during the synthesis process as well as further contribution by the elevated $\mathrm{Na}$ amount in the mine waters (Table 2). It is also noticeable that the Fe content in the zeolitic product obtained when AMD was used was higher than in the original fly ash when compared to the synthesis product obtained when pure water and circumneutral mine water had been used during the synthesis. The concentration of the other major element ( $\mathrm{Si}, \mathrm{Al}, \mathrm{Ca}, \mathrm{Mg}, \mathrm{K}, \mathrm{P}, \mathrm{Mn}$, and $\mathrm{Cr}$ ) and trace elements ( $\mathrm{Sr}, \mathrm{V}, \mathrm{Ce}, \mathrm{Zr}, \mathrm{Cr}, \mathrm{Y}, \mathrm{Nd}, \mathrm{Ni}, \mathrm{Co}, \mathrm{Th}, \mathrm{Zn}, \mathrm{Pb}, \mathrm{Nb}, \mathrm{U}, \mathrm{Cu}, \mathrm{Ga}$ and $\mathrm{Rb}$ ) were relatively lower in the synthesized zeolitic product than in the original fly ash, implying that these elements had reported to the post-synthesis supernatant. Si and Al, being the main elemental building units of the zeolite structure, had a higher concentration compared to the other elements. Elements such as $\mathrm{Ca}, \mathrm{Na}, \mathrm{Mg}, \mathrm{K}, \mathrm{Mn}, \mathrm{B}, \mathrm{Ni}$ and $\mathrm{V}$ could be expected to be available as exchangeable cations in the zeolitic matrix or even as discreet adsorbed particles even though it was not possible to determine this due to limitations of analysis. Since Fe and Ti have been reported to isomorphously substitute $\mathrm{Al}$ in the zeolitic framework (Weitkamp, 2000), higher ratios of incorporation of these elements in the zeolitic structure, especially from zeolites 
obtained from the used of acidic mine waters, could make this zeolites to have potential applications as catalysts for selective oxidation.

\section{Conclusion}

The results in this study have shown that different zeolites can be prepared using fly ash and mine waters. The type of zeolite formed was found to be dependent of the type of mine water used. From an environmental and economic point of view, the process developed in this study can not only reduce the environmental burden associated with these wastes but could also offer extra income generated from the sale of the synthesized zeolites. These findings are also expected to trigger research on the synthesis of zeolite from mine waters and fly ash using the waste heat generated in the coal power plants. Further studies will also shed more light on whether disposal of fly ash zeolites, rather than raw fly ash, would provide a safer option for disposing these two wastes after determining their leachability of toxic elements. It will also be of interest to investigate the potential for recyclability of the resulting post-synthesis supernatant back to the synthesis process.

\section{Acknowledgments}

The authors would like to acknowledge National Research Foundation (NRF), Eskom and University of the Western Cape for support and for providing the funds to make this study possible. 


\section{References}

Ahmaruzzaman, M., 2010. A review on the utilization of fly ash. Prog. Energy. Combust. Sci. 36, 327-363.

Belviso, C., Cavalcante, F., Fiore, S., 2010. Synthesis of zeolite from Italian coal fly ash: Differences in crystallization temperature using seawater instead of distilled water. Waste Manage. 30, 839-847.

Catalfamo, P., Pasquale, S.D., Corigliano, F., Mavilia, L., 1997. Influence of the calcium content on the coal fly ash features in some innovative applications. Resour. Conserv. Recycl. 20, 119-125.

Eskom (Electricity Supply Commission, South Africa) annual report, 2011. www.eskom.co.za. (accessed on 31.01.12).

Feng, D., Aldrich, C., Tan, H., 2000. Treatment of acid mine drainage by use of heavy metal precipitation and ion exchange. Miner. Eng. 13, 623-642.

Holler, H., Wirsching, U., 1985. Zeolite formation from fly ash. Fortschritte Miner. 63, 21-43.

Hui, K.S., Chao, C.Y.H., 2008. Methane emissions abatement by multi-ionexchanged zeolite a prepared from both commercial-grade zeolite and coal fly ash. Environ. Sci. Technol. 42, 7392-7397.

Inada, M., Tsujimoto, H., Eguchi, Y., Enomoto, N., Hojo, J., 2005. Microwave assisted zeolite synthesis from fly ash in hydrothermal process. Fuel 84, $1482-1486$.

Kutchko, B.G., Kim, A.G., 2006. Fly ash characterization by SEM-EDS. Fuel 85, 2537- 2544 .

Lee, D.B., Matsue, N., Henmi, T., 2001. Influence of $\mathrm{NaOH}$ concentrations dissolved in seawater and hydrothermal temperatures on the synthesis of artificial zeolite from coal fly ash. Clay Sci. 11, 451-463.

Lee, K., Jo, Y., 2010. Synthesis of zeolite from waste fly ash for adsorption of $\mathrm{CO}_{2}$. J. Mater. Cycles Waste Manage. 12, 212-219.

Madzivire, G., Petrik, L.F., Gitari, W.M., Ojumu, T.V., Balfour, G., 2010. Application of coal fly ash to circumneutral mine waters for the removal of sulphates as gypsum and ettringite. Miner. Eng. 23, 252-257.

Moreno, N., Querol, X., Ayora, C., 2001. Utilization of zeolites synthesized from coal fly ash for the purification of acid mine waters. Environ. Sci. Technol. $35,3526-3534$.

Murayama, N., Yamamoto, H., Shibata, J., 2002. Mechanism of zeolite synthesis from fly ash by alkali hydrothermal reaction. Int. J. Miner. Process. 64, 1-17.

Musyoka, N.M., Petrik, L.F., Balfour, G., Gitari, W.M., Hums, E., 2011. Synthesis of hydroxy sodalite from coal fly ash using waste industrial brine solution. J. Environ. Sci. Health Part A 46, 1-9.

Prasad, B., Mortimer, R., 2011. Treatment of acid mine drainage using fly ash zeolite. Water Air Soil Pollut. 218, 667-679. 
Querol, X., Moreno, N., Umaña, J.C., Alastuey, A., Hernández, E., López-Soler, A., Plana, F., 2002. Synthesis of zeolites from fly ash: an overview. Int. J. Coal Geol. 5O, 413-423.

Ríos, C.A., Williams, C.D., 2008. Synthesis of zeolitic materials from natural clinker: a new alternative for recycling coal combustion by-products. Fuel 87, 2482- 2492.

Vadapalli, V.R.K., Gitari, W.M., Ellendt, A., Petrik, L.F., Balfour, G., 2010. Synthesis of zeolite-P from coal fly ash derivative and its utilisation in mine-water remediation. South African J. Sci. 106, 62-68.

Weitkamp, J., 2000. Zeolites and catalysis. Solid State Ionics 131, 175-188. World coal association publication, The Coal Resource; A Comprehensive Overview of Coal, 2005. www.worldcoal.org/resources/wca-publications. (accessed on 31.01.12). 